\title{
Delayed Lung Maturation in the Macrosomic Offspring of Genetically Determined Diabetic $(\mathrm{db} /+)$ Mice $^{1}$
}

\author{
STEWART LAWRENCE, JOSEPH WARSHAW, AND HEBER C. NIELSEN \\ Departments of Pediatrics [S.L., J.W.]. University of Texas Southwestern Medical Center, Dallas, Texas 75235, \\ and Tufts University School of Medicine [H.C.N.J, New England Medical Center Hospital, \\ Boston, Massachusetts 02111
}

\begin{abstract}
We studied a genetically determined diabetes in pregnancy, the heterozygous diabetes $(\mathrm{db} /+)$ mouse. We found that fetal mice from these pregnancies are macrosomic with increased body, lung, and placenta wt, have altered organ protein, DNA and phospholipid content, and exhibit abnormal carbohydrate metabolism with increased liver and glycogen content. We further studied the effect of increased substrate availability and utilization on lung growth and maturation in $(\mathrm{db} /+)$ fetal mice, by measuring lung phospholipid synthesis as represented by the incorporation of the radiolabeled precursors, $\left[{ }^{3} \mathrm{H}\right]$ choline and $\left[{ }^{14}\right.$ Clglycerol, in fetal lung at 18 days' gestation (term $=$ 19). Diabetic fetuses incorporated significantly more $\left[{ }^{3} \mathrm{H}\right]$ choline into disaturated phosphatidylcholine than controls $\left(1.32 \pm 0.10 \times 10^{-2}\right.$ versus $0.78 \pm 0.05 \times 10^{-2} \mathrm{nmol} / \mathrm{g}$ protein/min, mean $\pm \mathrm{SE} ; \boldsymbol{p}<\mathbf{0 . 0 0 1}$, but significantly less $\left[{ }^{14} \mathrm{C}\right]$ glycerol into phosphatidylglycerol than controls $(3.18$ \pm 0.38 versus $4.91 \pm 0.53 \mathrm{nmol} / \mathrm{g}$ protein $/ \mathrm{min}$, mean $\pm \mathrm{SE}$; $p<0.002$ ), and their phosphatidylglycerol/phosphatidylinositol synthesis ratios were decreased $(1.81 \pm 0.18$ versus $3.17 \pm 0.14$; mean $\pm \mathrm{SE} ; p<0.001$ ). Diabetic fetal lungs appeared morphologically less mature than controls at 18 days' gestation, as shown by a significantly decreased air space density $(0.27 \pm 0.01$ versus $0.43 \pm 0.02$, mean $\pm \mathrm{SE}$; $p<0.001)$ and alveolar epithelial cell/total tissue ratio $(0.54 \pm 0.02$ versus $0.66 \pm 0.03$, mean $\pm \mathrm{SE} ; p<0.01)$. The increased synthesis of lung disaturated phosphatidylcholine in diabetic fetal mice may reflect the enhancement of body and lung growth in these macrosomic fetuses. Lung maturation, as represented by phosphatidylglycerol synthesis, the phosphatidylglycerol/phosphatidylinositol ratio, and morphologic indices, was abnormal in diabetic fetuses. The diabetic mouse is a useful model for studying the mechanisms resulting in enhanced growth and concomitant alterations in lung maturation in the infant of a diabetic mother. (Pediatr Res 25:173-179, 1989)
\end{abstract}

\section{Abbreviations}

RDS, respiratory distress syndrome PC, phosphatidylcholine

SPC, disaturated phosphatidylcholine

$\mathrm{S}$, sphingomyelin

Received May 23, 1988; accepted October 11, 1988

Correspondence and reprint requests Heber C. Nielsen, M.D., Department of Pediatrics Box 97. New England Medical Center, 750 Washington Street, Boston, MA 02111.

Supported by Grant HL-29722 from the National Institute of Health.

Presented in part at the 54th Annual Meeting of the Society for Pediatric

Research, Washington, DC, in May 1985, and at the 56th Annual Meeting of the Society for Pediatric Research, Anaheim, CA, in April 1987.

\author{
PI, phosphatidylinositol \\ PE, phosphatidylethanolamine \\ PS, phosphatidylserine \\ PG, phosphatidylglycerol
}

Human fetal development during maternal diabetes is abnormal, frequently resulting in obese, macrosomic newborns with delayed maturation of various organ systems. Infants of diabetic mothers whose hyperglycemia is inadequately controlled late in gestation appear to have an increased risk of lung immaturity, as manifested by RDS at birth (1). Animal models in which maternal glucose intolerance and consequent fetal hyperglycemia are artificially induced have been developed to study this phenomenon (2). However, important questions concerning maternal-fetal interactions in diabetes and the consequent effects on fetal organ growth and development might be more appropriately addressed by using a model in which the diabetes is genetically determined, therefore occurring spontaneously in the mother (2).

The diabetic mouse $(\mathrm{db} / \mathrm{db})$ is a well-described model of genetic diabetes transferred as an autosomal recessive trait. Homozygous (db/db) animals exhibit visible obesity in infancy with marked hyperglycemia and insulin resistance, followed later by hypoinsulinemia and profound diabetes at 3-4 mo of age (3). As the adult $(\mathrm{db} / \mathrm{db})$ mouse is infertile, heterozygous animals must be bred to produce offspring. The heterozygous female $(\mathrm{db} /$ +) exhibits normal glucose tolerance except during pregnancy, when abnormal glucose tolerance, postprandial hyperglycemia and elevated $\mathrm{Hb} A 1 \mathrm{C}$ levels are present $(4,5)$.

We have studied the fetus of the pregnant heterozygous $(\mathrm{db} /$ + ) female to learn more about growth and the development during pregnancy complicated by abnormal glucose metabolism. In this report, we describe our results in characterizing abnormal fetal growth during the $(\mathrm{db} /+)$ pregnancy and examine how altered fetal growth may affect maturation. First, we evaluated fetal size, various aspects of glucose metabolism, and organ growth to determine how these fetuses were affected by maternal glucose intolerance. We found the fetuses to be macrosomic with altered body and organ weights, and to exhibit alterations in glucose metabolism, and in protein, DNA and phospholipid content.

Next, we hypothesized that increased substrate availability and utilization with consequent macrosomia would result in alterations in fetal lung growth and maturation in the mouse fetus of $\mathrm{a}(\mathrm{db} /+)$ pregnancy. Lung growth and maturation were assessed by measuring the synthesis in fetal lung slices of PC, SPC, and $\mathrm{PG}$, the phospholipids, present in largest quantities within extracellular surfactant. Further, we evaluated the morphologic ma- 
turity of the fetal lung by a morphometric analysis of the relative amount of epithelium, connective tissue, and air space in fetal lung tissue.

\section{MATERIALS AND METHODS}

Animal model. Adult male and female heterozygous diabetic $(\mathrm{db} /+)$ mice were obtained from The Jackson Laboratory (Bar Harbor, ME) and were caged together at night. Mating was confirmed by the presence of a copulatory plug in the morning; this day was designated day 0 of gestation (term: 19 days). Animals subsequently were killed for study by decapitation on days 17 or 18 of gestation, or as newborns on the 1st day of life.

Two different strains of mice were initially studied to establish the appropriate controls. The $\mathrm{db}$ gene, after its identification at The Jackson Laboratory, was bred onto the C57BL/KsJ genetic strain, into which the gene for the coat color marker misty was also introduced (6). The misty gene, a recessive trait, codes for a gray coat color and has a chromosomal locus very close to the $\mathrm{db}$ gene. It is used as a marker for determining the heterozygous $(\mathrm{db} /+)$ state $(6)$. In early studies, we used both the C57BL/KsJ $(++/++)$ black mouse and homozygous misty mice $(\mathrm{m}+/+\mathrm{m})$ for controls, as it was unclear which would be an appropriate control. In later studies, only misty mice were used as controls as we found no important differences in comparison.

When the mice were killed, uteri were rapidly removed and placed on ice, and fetuses were rapidly removed, weighed, and treated in one of three ways. In one group of experiments, samples of blood were taken for glucose analysis $(5 \mu \mathrm{l})$ or for insulin assay ( $>100 \mu \mathrm{l}$, pooled between fetuses) from neck veins. Fetal pancreatic tissue was also obtained for insulin assay. Lungs, placenta, and a portion of liver were obtained, weighed, and stored at $-40^{\circ} \mathrm{C}$ for subsequent measurements of phospholipid, protein, and DNA content. In a second group of experiments, placenta, lungs, and a sample of liver were obtained for glycogen assay as specified below. For a third group, the lungs were dissected free of nonpulmonary tissue for immediate assay of phospholipid synthesis.

Phospholipid synthesis in lung slices. The rate of phosphatidylcholine synthesis in lung slices was determined by measuring the rate of incorporation of $\left[{ }^{3} \mathrm{H}\right]$ choline into PC. PG and PI synthesis were determined by measuring the rate of incorporation of $\left[{ }^{14} \mathrm{C}\right]$ glycerol into PG and PI. Lungs were removed from fetuses and placed immediately into ice-cold Krebs-Ringer bicarbonate buffer ( $\mathrm{pH} 7.4$ ), previously flushed with $95 \% \mathrm{O}_{2}$ for $20 \mathrm{~min}$. Lung slices $(0.5-\mathrm{mm}$ thick) were prepared on a McIlwain tissue chopper (Brinkmann Instruments, Westbury, NY) and placed in 10 -ml flasks containing $5 \mathrm{ml}$ of the Krebs-Ringer bicarbonate buffer. After preincubation for $10 \mathrm{~min}$ at $37^{\circ} \mathrm{C}$ in a shaking water bath, either $2 \mu \mathrm{Ci}\left[{ }^{3} \mathrm{H}\right]$ choline (sp act, $60 \mathrm{Ci} / \mathrm{mmol}$ ) or $1 \mu \mathrm{Ci}$ $\left[{ }^{14} \mathrm{C}\right]$ glycerol (sp act, $40 \mathrm{mCi} / \mathrm{mmol}$ ) (New England Nuclear, Boston, MA) was added to each flask. The incubation was terminated after $60 \mathrm{~min}$ by placing the flasks on ice and washing the tissue 5 times with ice-cold $0.9 \% \mathrm{NaCl}$. The lungs were then frozen and stored at $-40^{\circ} \mathrm{C}$ for later lipid extraction and analysis. Preliminary experiments showed that the incorporation of $\left[{ }^{3} \mathrm{H}\right]$ choline into PC and SPC and of $\left[{ }^{14} \mathrm{C}\right]$-glycerol into $\mathrm{PG}$ was linear over at least $3 \mathrm{~h}$.

Lipid extraction and analysis. Lungs and livers were homogenized in $0.9 \% \mathrm{NaCl}$ by hand in a Potter-Elvehjem apparatus, (Fisher Scientific, Pittsburgh, PA), and lipids were extracted from tissue homogenates with chloroform and methanol by the method of Folch et al. (7). An aliquot of the extract of lung, liver, and of lung slices incubated with $\left[{ }^{3} \mathrm{H}\right]$ choline was further reacted with osmium tetroxide to separate saturated SPC from total PC as described by Mason et al. (8). PC, S, and SPC were isolated by thin-layer chromatography on silica gel $\mathrm{H}$ thin-layer chromatography sheets (Eastman Kodak Co., Rochester, NY) in chloroform-methanol-water 65:25:4 (9). The resulting PC and SPC spots were visualized by exposure to iodine vapor. PG, PI,
PE, and PS, were isolated by thin-layer chromatography using silica gel $G$ preabsorbent plates (Analtech, Newark, DE) in chloroform-ethanol-water-triethylamine 60:68:16:70 (10). The resulting spots were visualized by charring at $100^{\circ} \mathrm{C}$ after lightly spraying with $5 \%$ sulfuric acid.

Total phospholipids (PC, SPC, S, PG, PI, PE, and PS) were measured by assay of inorganic phosphorus (11). Labeled PC, SPC, PG, and PI were quantitated by scintillation counting in $10 \mathrm{ml}$ of a toluene-1,4-bis(5-phenyloxazol-2-yl)benzene base scintillation cocktail.

Glucose analysis. Fetal blood glucose was measured by a microglucose oxidase assay (4) modified by us for very small samples and using prepared enzymes obtained from Sigma Chemical Co. (St. Louis, MO). Blood was collected in $5-\mu 1$ capillary tubes and quickly transferred to a microtainer containing $70 \mu \mathrm{l}$ of $2 \%$ perchloric acid. After gentle mixing, samples were spun for $4 \mathrm{~min}$ in a microcentrifuge, and $50 \mu \mathrm{l}$ of supernatant was used. To this sample were added $2 \mathrm{ml}$ of PGO enzyme solution (containing $1.6 \mathrm{ml}$ of a solution containing $50 \mathrm{mg} O$ dianisidine dihydrochloride dissolved in $20 \mathrm{ml}$ of water, 1 capsule of PGO enzymes, and $100 \mathrm{ml}$ of water). The mixture was incubated at $37^{\circ} \mathrm{C}$ in a water bath for $30 \mathrm{~min}$, and the spectrophotometric absorption at $450 \mathrm{~nm}$ was measured. Preliminary experiments showed this method to exhibit less than $5 \%$ variability on duplicate samples and to be linear at glucose concentrations of $0-500 \mathrm{mg} / \mathrm{ml}$.

Glycogen analysis. Samples of liver and whole placenta and lung were rapidly weighed, flash-frozen in a solid $\mathrm{CO}_{2}$-methanol bath, and stored at $-40^{\circ} \mathrm{C}$ until analysis. Glycogen content was measured by the method of Maniscalso et al. (12) in which $\mathrm{NADPH}$, generated during the reaction in glycogenolysis, whereby glucose-6-phosphate is modified to 6-phosphogluconolactone, is detected fluorometrically.

Insulin analysis. Samples of blood were collected in $20 \mu 1$ tubes from separate fetuses and immediately pooled in a microtainer containing Trasylol (FBA Pharmaceuticals, New York, NY) 100 $\mathrm{U}$, and $0.24 \mathrm{mg}$ EDTA in a vol of $20 \mu \mathrm{l}$. A total vol of 100-200 $\mu \mathrm{l}$ of blood/tube was obtained from four to eight fetuses and used for each assay. The pooled samples of Trasylol and EDTA were spun for $2 \mathrm{~min}$ in a microcentrifuge, and the supernatant was stored at $-40^{\circ} \mathrm{C}$. The fetal pancreas was removed intact, flash-frozen in a solid $\mathrm{CO}_{2}$-methanol bath, and stored at $-40^{\circ} \mathrm{C}$. Tissues were later lyophilized, weighed, and extracted in acid alcohol for measurement of insulin content. Insulin assay was performed by the kind courtesy of Dr. C. P. Fawcett, Southwestern Medical School (Dallas, TX), using the procedure of Herbert et al. (13).

Protein and DNA analysis. Total protein was measured by the Lowry method using BSA as standard (14). DNA was assayed by the method of Burton (15), using deoxyribose as the standard.

Morphology. Lungs for morphologic analysis were taken immediately after killing from randomly selected fetuses. Sections from the right upper lobe were stained with hematoxylin and eosin and examined at $40 \times$ magnification with a light microscope containing an eyepiece grid with 100-point intersections. Four randomly selected fields per lung were examined. The slides were

Table 1. Body, lung, and placenta wt of 18-day fetuses*

\begin{tabular}{lccc}
\hline & $(\mathrm{db} /+)$ group & Misty group & C57BL/KsJ group \\
\hline Body wt $(\mathrm{g})$ & $1.091 \pm 0.090 \dagger$ & $1.022 \pm 0.128$ & $1.036 \pm 0.088$ \\
& $(n=62)$ & $(n=41)$ & $(n=30)$ \\
Lung wt $(\mathrm{mg})$ & $39.0 \pm 10.1 \neq$ & $32.1 \pm 5.7$ & $36.9 \pm 7.15$ \\
& $(n=64)$ & $(n=40)$ & $(n=30)$ \\
Placenta wt $(\mathrm{mg})$ & $91.60 \pm 16.3 \dagger$ & $83.3 \pm 10.7$ & $79.7 \pm 9.5$ \\
& $(n=58)$ & $(n=40)$ & $(n=30)$ \\
\hline
\end{tabular}

* Data are expressed as means $\pm \mathrm{SD}$.

$\dagger p<0.005,(\mathrm{db} /+)$ group versus misty group.

$\ddagger p<0.001,(\mathrm{db} /+)$ group versus misty group. 
coded such that the examiner was unaware of the source of the lung. Only areas of peripheral lung were examined; any fields including large airways or blood vessels were excluded from analysis. Each point on the grid was scored as: 1) airspace or lumen; 2) epithelium; or 3) connective tissue or interstitium. The data were expressed as the vol density occupied by each component.

Statistical methods. Data for diabetic and control fetuses were compared using the unpaired Student's $t$ test (16). Data are presented as the mean $\pm 1 \mathrm{SD}$ unless otherwise noted.

\section{RESULTS}

Fetal growth. We found no increase in fetal death in the $(\mathrm{db} /$ +) pregnancies in comparison to the misty or the C57BL/KsJ pregnancies. Similarly, neonatal survival of the three groups did not appear to be different.

Fetuses of $(\mathrm{db} /+)$ pregnancies at 18 days of gestation had significantly greater body, lung, and placenta wt than either fetuses of misty pregnancies or of C57BL/KsJ pregnancies (Table 1). The relative differences between the $(\mathrm{db} /+)$ group and the misty group were $7 \%$ for body wt, $10 \%$ for placenta wt, and $20 \%$ for lung wt. The two control groups were not significantly different from each other. At 17 days' gestation, there were even larger differences between the $(\mathrm{db} /+)$ group and the misty group for body wt $(0.859 \pm 0.137$ versus $0.667 \pm 0.059 \mathrm{~g})$ and for lung wt $(29.1 \pm 7.2$ versus $17.1 \pm 0.8 \mathrm{mg})$, but not for placenta wt $(81.4 \pm 14.3$ versus $82.2 \pm 10.8 \mathrm{mg})$. Fetuses of $\mathrm{C} 57 \mathrm{BL} / \mathrm{KsJ}$ were not studied at 17 days.

Table 2 shows the DNA and protein content of lung, liver, and placenta in the $(\mathrm{db} /+)$ and misty groups at 18 days of gestation. The observed differences between the diabetic and control groups were not consistent from organ to organ. Placentas of the $(\mathrm{db} /+)$ group had a significantly lower DNA concentration than the misty group, but the protein concentrations were similar. The livers of the $(\mathrm{db} /+)$ group were shown to have both lower protein and lower DNA concentrations than the misty group. There were no observed differences in protein or DNA concentration of the lung.

Glucose metabolism. Blood glucose and plasma and pancreas insulin concentrations are shown for the diabetic and the misty groups in Table 3. Fetuses of $(\mathrm{db} /+)$ pregnancies had a lower mean blood glucose concentration than fetuses of the misty pregnancies. This is similar to what has been shown for newborns in the first few days of life (6). Plasma insulin values were slightly higher in the $(\mathrm{db} /+)$ group, but the difference was not statistically significant, possibly due to a small sample size. Offspring of $(\mathrm{db} /$ +) mothers exhibit elevated plasma insulin levels in the first few days of life (6). It should be noted that our insulin measurements were performed on samples of blood pooled from most or all fetuses in a litter. Pancreatic insulin content was significantly lower in fetuses of $(\mathrm{db} /+)$ pregnancies than in fetuses of misty pregnancies.

Organ glycogen content at 17 and 18 days' gestation is shown in Figure 1. The results on day 17 exhibit no significant differences between the $(\mathrm{db} /+)$ group and the misty group for lung, liver, or placenta. On day 18 , the lung glycogen content was still not significantly different between the two groups. However, fetuses of $(\mathrm{db} /+)$ pregnancies had a significantly higher concentration of glycogen in both the liver and the placenta. The changes within groups from day 17 to 18 exhibit a tendency for glycogen to overaccumulate between days 17 and 18 of gestation in the $(\mathrm{db} /+)$ group in both the liver and the placenta, whereas glycogen stores at day 18 are only slightly higher in the livers of the misty group and are being rapidly depleted in the placentas. However, this pattern was not demonstrated in the lung. Glycogen content at 19 days' gestation (the day of birth) continued to show the overall trend of decreasing content with approaching parturition and extrauterine metabolism, with both the $(\mathrm{db} /+)$ and misty groups exhibiting considerably lower values in lung, liver, and placenta, with no remaining group differences.

Phospholipid content. Phospholipid profiles of the $(\mathrm{db} /+)$ and misty groups at 18 days for the lung and the liver are shown in

Table 3. Blood glucose, plasma insulin, pancreatic insulin content*

\begin{tabular}{|c|c|c|c|}
\hline & $\begin{array}{c}\text { Blood glucose } \\
\mathrm{mg} / 100 \mathrm{ml}\end{array}$ & $\begin{array}{l}\text { Plasma insulin } \\
\mu \mathrm{U} / \mathrm{ml} \text { plasma }\end{array}$ & $\begin{array}{c}\text { Pancreas insulin } \\
\mathrm{mU} / \mathrm{mg} \\
\text { pancreas }\end{array}$ \\
\hline$(\mathrm{db} /+)$ group & $\begin{array}{c}40.4 \pm 15.5 \dagger \\
(n=67)\end{array}$ & $\begin{array}{c}56.2 \pm 14.3 \ddagger \\
(n=6)\end{array}$ & $\begin{array}{c}11.0 \pm 5.5 \S \\
(n=53)\end{array}$ \\
\hline Misty group & $\begin{array}{c}49.3 \pm 14.5 \\
(n=31)\end{array}$ & $\begin{array}{c}44.0 \pm 19.7 \\
(n=6)\end{array}$ & $\begin{array}{c}17.0 \pm 4.3 \\
(n=29)\end{array}$ \\
\hline
\end{tabular}

* Data are expressed as means \pm SD.

$\dagger p<0.01,(\mathrm{db} /+)$ group versus misty group.

$\ddagger 0.20>p>0.10,(\mathrm{db} /+)$ group versus misty group.

$\S p<0.001,(\mathrm{db} /+)$ group versus misty group.

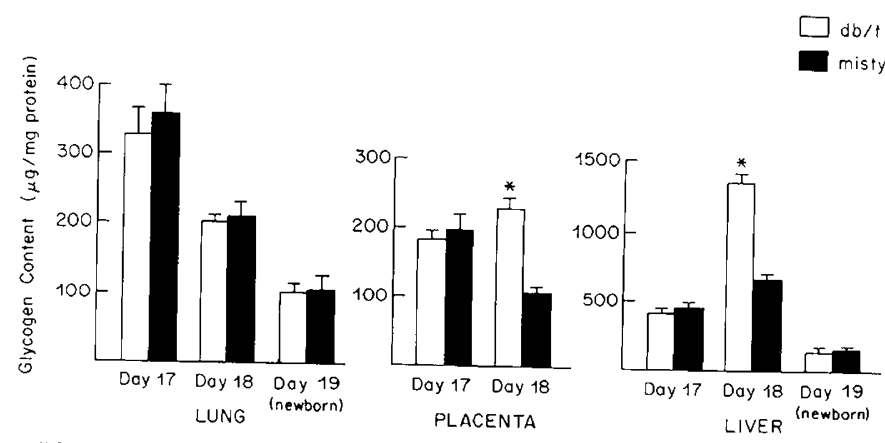

Fig. 1. Fetal organ glycogen content at days 17, 18, and 19 of gestation. Day 19 animals were newborn. Statistical comparisons were made between the $(\mathrm{db} /+)$ and misty groups at each gestational age. Bars represent the mean $\pm \mathrm{SE}$. Sample sizes: for the $(\mathrm{db} /+)$ group, $n=14$ for day-17 lung; $n=8$ for day-17 liver; $n=4$ for day-17 placenta; $n=39$ for day-18 lung; $n=19$ for day-18 liver; $n=21$ for day- 18 placenta; $n=$ 4 for day-19 lung; and $n=8$ for day-19 liver; for the misty group, $n=$ 18 for day- 17 lung; $n=17$ for day-17 liver; $n=15$ for day- 17 placenta; $n=28$ for day-18 lung; $n=27$ for day- 18 liver; $n=28$ for day- 18 placenta; $n=12$ for day-19 lung; and $n=6$ for day-19 liver. *, significantly different from control, $p<0.0001$.

Table 2. DNA and protein concentrations of lung, liver, and placenta*

\begin{tabular}{|c|c|c|c|c|c|c|}
\hline & \multicolumn{2}{|c|}{ Placenta } & \multicolumn{2}{|c|}{ Liver } & \multicolumn{2}{|c|}{ Lung } \\
\hline & $\begin{array}{c}\text { DNA } \\
\mathrm{nmol} / \mathrm{mg} \mathrm{wt}\end{array}$ & $\begin{array}{l}\text { Protein } \\
\mu \mathrm{g} / \mathrm{mg} \text { wt }\end{array}$ & $\begin{array}{c}\text { DNA } \\
\mathrm{nmol} / \mathrm{mg} \text { wt }\end{array}$ & $\begin{array}{c}\text { Protein } \\
\mu \mathrm{g} / \mathrm{mg} \mathrm{wt}\end{array}$ & $\begin{array}{c}\text { DNA } \\
\mathrm{nmol} / \mathrm{mg} \text { wt }\end{array}$ & $\begin{array}{l}\text { Protein } \\
\mu \mathrm{g} / \mathrm{mg} \mathrm{wt}\end{array}$ \\
\hline$(\mathrm{db} /+)$ group & $\begin{array}{c}1.84 \pm 0.17 \dagger \\
(n=21)\end{array}$ & $\begin{array}{c}42.2 \pm 5.7 \\
(n=21)\end{array}$ & $\begin{array}{c}13.1 \pm 1.0 \dagger \\
(n=35)\end{array}$ & $\begin{array}{c}136.8 \pm 12.9 \dagger \\
(n=35)\end{array}$ & $\begin{array}{c}16.5 \pm 2.6 \\
(n=51)\end{array}$ & $\begin{array}{c}111.1 \pm 18.4 \\
(n=51)\end{array}$ \\
\hline Misty group & $\begin{array}{c}2.03 \pm 0.17 \\
(n=28)\end{array}$ & $\begin{array}{c}42.3 \pm 5.2 \\
(n=28)\end{array}$ & $\begin{array}{r}15.6 \pm 2.5 \\
(n=28)\end{array}$ & $\begin{array}{c}157.0 \pm 10.5 \\
(n=28)\end{array}$ & $\begin{array}{c}15.7 \pm 1.9 \\
(n=28)\end{array}$ & $\begin{array}{c}103.8 \pm 10.0 \\
(n=28)\end{array}$ \\
\hline
\end{tabular}

* Data are expressed as means \pm SD.

$\dagger p<0.001,(\mathrm{db} /+)$ group versus misty group. 
Figures 2 and 3. In the liver, increased amounts of PC, PE, and PS were found in the $(\mathrm{db} /+)$ group. Increased amounts of PC and PE were also present in the lungs of the $(\mathrm{db} /+)$ group as well as increased S and PI content. The misty group had more lung phosphatidylglycerol and a higher PG/PI ratio. Because of differences in liver protein concentrations between the two groups, phospholipid content/mg tissue wt was also computed for both lung and liver. Qualitatively similar results were found (data not shown).

Phospholipid synthesis. The incorporation of $\left[{ }^{3} \mathrm{H}\right]$ choline into PC and SPC in fetal lung slices at 17 and 18 days' gestation is shown in Table 4. The incorporation of labeled choline into PC was slightly higher for the $(\mathrm{db} /+)$ group on both days, but this was not statistically significant. However, choline incorporation into SPC was increased by $60 \%$ in $(\mathrm{db} /+)$ fetal lung slices at 18 days' gestation. The incorporation of $\left[{ }^{14} \mathrm{C}\right]$ glycerol into $\mathrm{PG}$ was significantly decreased in fetal lungs of the $(\mathrm{db} /+)$ group on day 18 , as was the ratio of $\mathrm{PG} / \mathrm{PI}$ synthesis (Table 5).

Morphology. Typical sections of lung from the $(\mathrm{db} /+)$ and control groups at 18 days' gestation are shown in Figures 4 and 5. The diabetic fetal lung had the appearance of delayed morphologic maturation with thicker septal walls and decreased airspace density and epithelial cell/total tissue ratio. Morphometric analysis, shown in Table 6 , confirms these apparent differences. Fetal lungs of the $(\mathrm{db} /+)$ group had a significantly decreased airspace density and epithelial cell/total tissue ratio.

\section{DISCUSSION}

The typical infant of a diabetic mother-exhibiting obesity, macrosomia, and delayed maturation of various organ systems

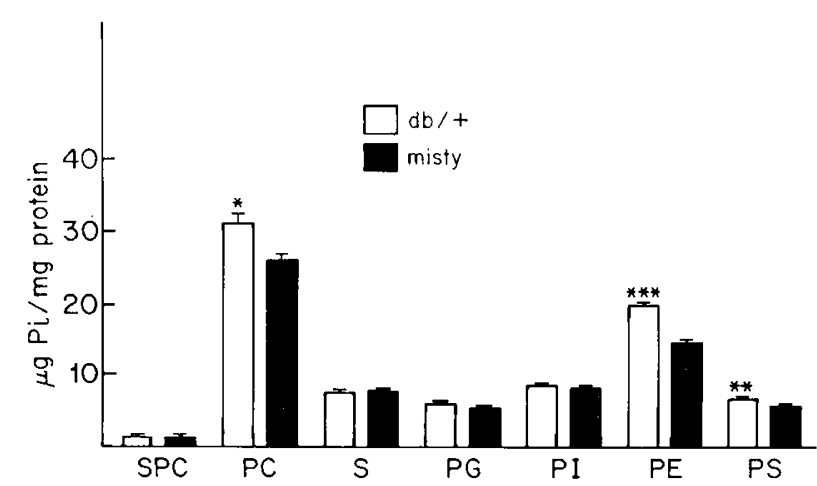

Fig. 2. Liver phospholipid content at day 18 of gestation. Statistical comparisons were made between the $(\mathrm{db} /+)$ and misty groups. Bars represent the mean $\pm \mathrm{SE}$. For the $(\mathrm{db} /+)$ group, $n=21-35$; for the control group, $n=21-28$. *, significantly different from control, $p<$ $0.01 ;{ }^{* *}, p<0.001{ }^{* * *}, p<0.0001$.

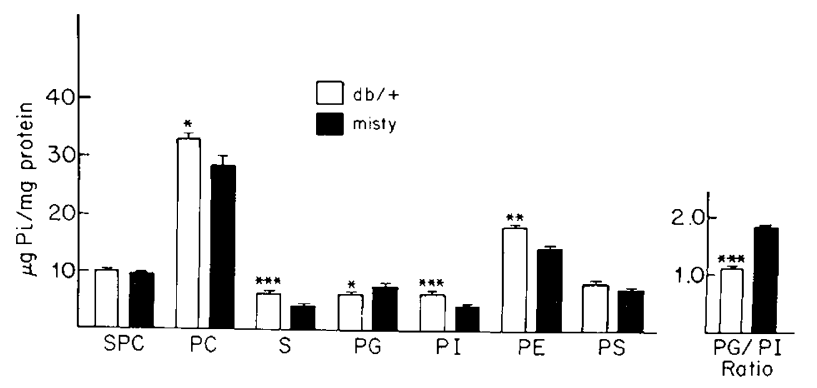

Fig. 3. Lung phospholipid content at day 18 of gestation. Statistical comparisons were made between the $(\mathrm{db} /+)$ and misty groups. Bars represent the mean $\pm \mathrm{SE}$. For the $(\mathrm{db} /+)$ group, $n=41$; for the misty group, $n=28$. $^{*}$, significantly different from control, $p<0.01 ;{ }^{* *}, p<$ $0.001 ; * * *, p<0.0001$.
Table 4. $\left.{ }^{3} \mathrm{H}\right]$ choline incorporation into PC and SPC in day-17 and -18 fetal lungs*

\begin{tabular}{cccc}
\hline Day & PC fraction & Misty group & $(\mathrm{db} /+)$ group \\
\hline 17 & PC & $4.68 \pm 0.69 \times 10^{-2}$ & $5.35 \pm 0.86 \times 10^{-2}$ \\
& & $(n=22)$ & $(n=13)$ \\
& SPC & $4.74 \pm 1.34 \times 10^{-3}$ & $4.82 \pm 0.62 \times 10^{-3}$ \\
& & $(n=22)$ & $(n=12)$ \\
18 & PC & $6.97 \pm 0.61 \times 10^{-2}$ & $7.40 \pm 0.85 \times 10^{-2}$ \\
& SPC & $(n=24)$ & $(n=24)$ \\
& & $0.78 \pm 0.05 \times 10^{-2}$ & $1.32 \pm 0.10 \times 10^{-2} \dagger$ \\
& & $(n=24)$ & $(n=24)$ \\
\hline
\end{tabular}

* Incorporation of $\left[{ }^{3} \mathrm{H}\right]$ Choline into PC and SPC in lung slices from 17- and 18-day fetuses of $(\mathrm{db} /+)$ and misty pregnancies. Data are expressed as nmol choline incorporated/g protein $/ \mathrm{min}$; means $\pm \mathrm{SE}$.

$\dagger p<0.001,(\mathrm{db} /+)$ group versus misty group.

Table 5. $\left[{ }^{14} C l\right.$ glycerol incorporation into $P G$ and $P I$ in day- 18 fetal lung*

\begin{tabular}{lcc}
\hline & Misty group & $(\mathrm{db} /+)$ group \\
\hline PG & $4.91 \pm 0.53$ & $3.18 \pm 0.38 \dagger$ \\
& $(n=12)$ & $(n=13)$ \\
PI & $1.54 \pm 0.15$ & $1.71 \pm 0.18$ \\
& $(n=12)$ & $(n=13)$ \\
PG/PI ratio & $3.70 \pm 0.14$ & $1.81 \pm 0.18 \ddagger$ \\
& $(n=12)$ & $(n=13)$ \\
\hline
\end{tabular}

* Incorporation of $\left[{ }^{14} \mathrm{C}\right]$ glycerol into PG and PI in lung slices from day 18 fetuses of $(\mathrm{db} /+)$ and misty pregnancies. The PG/PI ratio was calculated from the synthesis of PG and PI. Data are expressed as nmol glycerol incorporated $/ \mathrm{g}$ protein $/ \mathrm{min}$; means $\pm \mathrm{SE}$.

$\dagger p<0.002,(\mathrm{db} /+)$ group versus misty group.

$\ddagger p<0.001,(\mathrm{db} /+)$ group versus misty group.

including the lung and liver-is familiar to neonatal and perinatal care givers. The possible cause(s) of these potential abnormalities of development have been intensely discussed. Pederson et al. (17) proposed that maternal hyperglycemia and resulting fetal hyperglycemia led to fetal hyperinsulinemia which in turn stimulated growth and delayed functional maturation.

Most experimental models which have been developed to study fetal growth and development during maternal diabetes are limited by one or more difficulties. For example, the "diabetic" state may have been artificially arrived at by either eliminating maternal insulin production or by giving large amounts of glucose or insulin to mother or fetus (2). Fetuses of some of these models (notably the streptozotocin-treated rat with profound maternal and fetal hyperglycemia) are actually small for gestational age rather than macrosomic (18). It is therefore not clear that these models reflect the multiple physiologic and metabolic abnormalities which accompany true diabetes. Finally, as the altered glucose homeostasis in these models is not genetically determined, the possibility that the fetal genetic makeup plays a role in determining fetal response to maternal diabetes cannot be considered.

Many, if not all, of these problems in animal models of maternal diabetes could be overcome with the development of a genetically determined, naturally occurring diabetic state. The pregnant $(\mathrm{db} /+)$ mouse and its fetal offspring represent such a model. The diabetes in this animal is caused by insulin resistance, is an inherited trait, and interestingly, is active in the adult female only during pregnancy $(4,5)$. Approximately $3 / 4$ of the fetuses carry either one $(\approx 50 \%)$ or two $(\approx 25 \%)$ of the diabetic genes.

Some of the metabolic characteristics of this model are not typical for the severe juvenile-onset diabetes of the human (White classifications $\mathrm{C}, \mathrm{D}$, and $\mathrm{F}$ ). The facts that the diabetes is caused by insulin resistance rather than depletion, that fetal blood glucose is lower than control, and that the pancreatic insulin content of the fetus is decreased are all important variations from the $C, D$, and $F$ diabetic pregnancies. The model may 


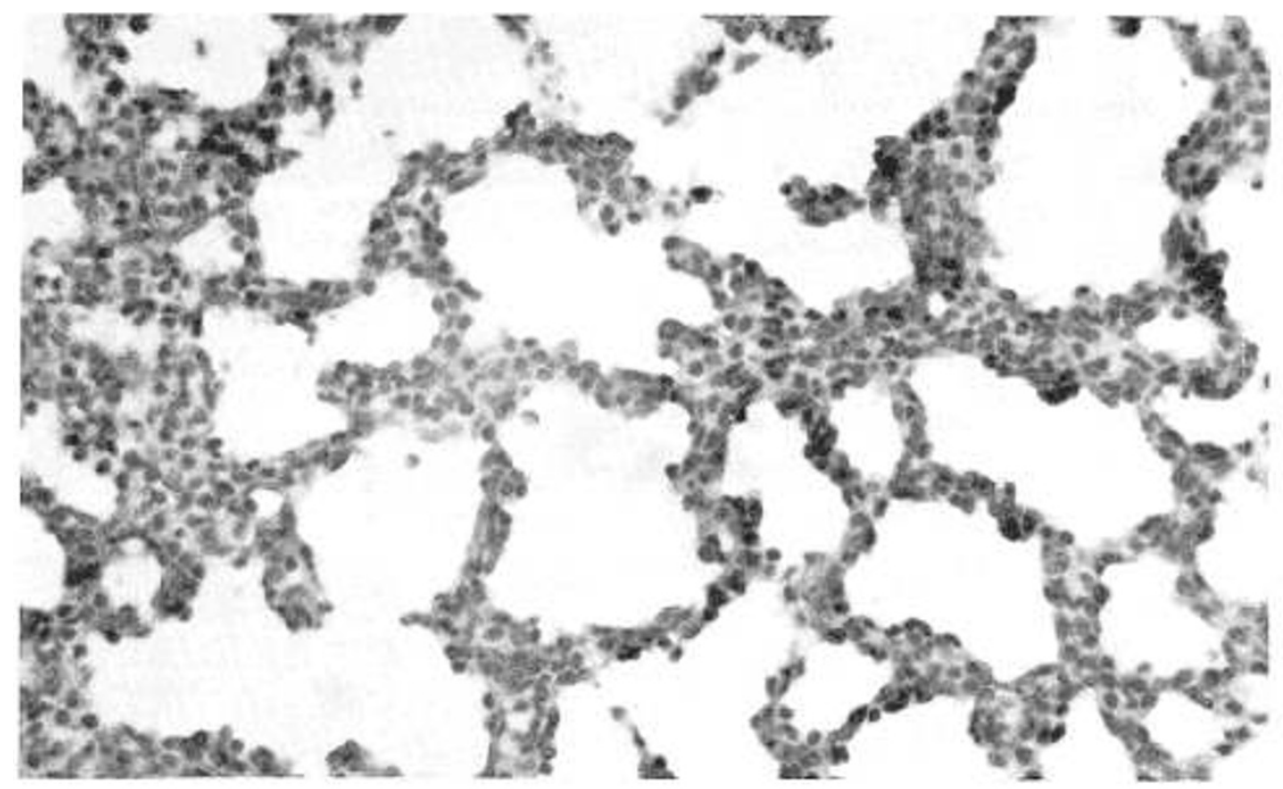

Fig. 4. Light microscopy of the lung of a control fetal mouse at 18 days' gestation (hematoxylin and eosin stain, $\times 40$ ).

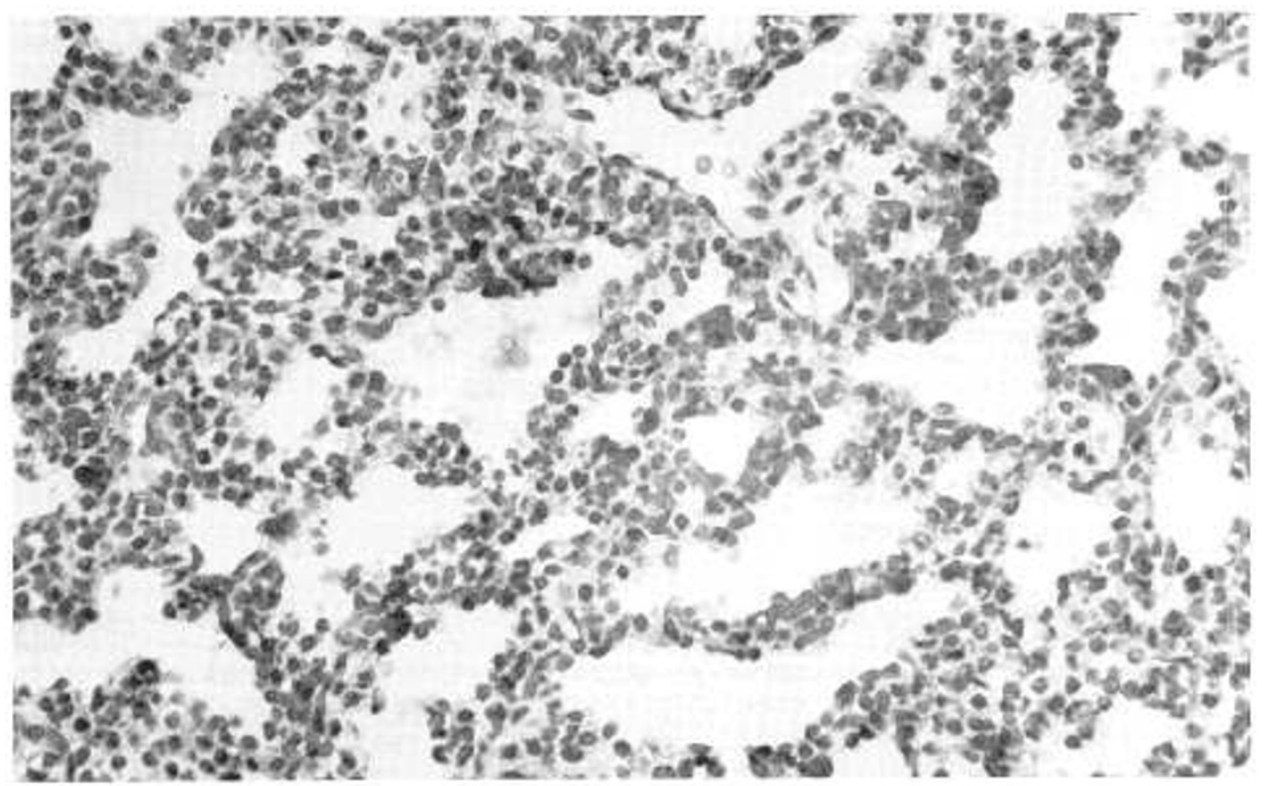

Fig. 5. Light microscopy of the lung of a diabetic $(\mathrm{db} /+)$ fetal mouse at 18 days' gestation (hematoxylin and eosin stain, $\times 40)$.

Table 6. Morphologic analysis of day-18 fetal lung*

\begin{tabular}{ccc}
\hline & Misty group & $(\mathrm{db} /+)$ group \\
\hline Airspace density & $0.43 \pm 0.02$ & $0.27 \pm 0.01 \dagger$ \\
& $(n=4)$ & $(n=4)$ \\
Epithelial cell/total tissue & $0.66 \pm 0.03$ & $0.54 \pm 0.02 \ddagger$ \\
& $(n=4)$ & $(n=4)$ \\
\hline
\end{tabular}

* Morpholigic analysis under light microscopy at $40 \times$ magnification of 18-day fetal lungs. A 100-point eyepiece grid was used, and the intersection of grid points with tissue or airspace were counted. Four fields were evaluated for each of four fetal lungs. Data are expressed as means \pm SE.

$\dagger p<0.001,(\mathrm{db} /+)$ group versus misty group

$\ddagger p<0.01,(\mathrm{db} /+)$ group versus misty group.

indeed be much more comparable with White's class A diabetes, or with gestational diabetes, in which many of these metabolic characteristics are also present (19).

Several aspects of the fetuses of the $(\mathrm{db} /+)$ pregnancies, as identified in this study, are worthy of note. First, the fetuses are quite obviously macrosomic, consistent with the observations of Kaufman et al. (5) on the newborn mice. The increases in body, placenta, and lung wt provide important physical evidence of altered fetal growth and development during a diabetic pregnancy, and therefore it may be appropriate to use this model to consider the interplay of growth and differentiation and the mechanisms that control each.

The metabolic characteristics of these animals suggest that the fetus is subjected to recurring bouts of transient hyperglycemia. Kaufman et al. (5) showed that while maternal fasting blood glucose is normal (confirmed by Nielsen HC, unpublished data), glucose tolerance is abnormal with elevated blood glucose continuing for 3 or more $h$ after a glucose load. In this study, the fetuses of $(\mathrm{db} /+)$ pregnancies exhibited a lower blood sugar, possible hyperinsulinemia, and decreased pancreatic insulin stores. This is in agreement with studies showing that newborns of $(\mathrm{db} /+)$ pregnancies at 3-5 days postnatal age are hyperinsulinemic and have lower blood sugars than control newborns (6). Similarly, Cuezva et al. (20) studied offspring of streptozotocin- 
treated rats in whom mild to moderate hyperglycemia was achieved by insulin treatment of the diabetic mother; they found the coincidence of high serum insulin and low pancreatic insulin levels. Bourbon et al. (21) described a mildly diabetic rat after streptozotocin injection with fetal hyperinsulinemia but normal blood glucose. We interpret our findings as evidence of abnormally increased fetal substrate metabolism caused by intermittent exposure to elevated glucose concentrations.

Further evidence of an alteration in substrate energy metabolism is found in the liver and placenta glycogen concentrations. The fetal mouse or rat begins to mobilize lung, liver, and placental glycogen 1 to 2 days before birth $(18,22-24)$. Gewolb and coworkers $(18,23)$ found that this normal glycogen breakdown was delayed in fetuses of the streptozotocin rat model due to altered activity of enzymes in the gluconeogenesis and glycogenolysis pathways. Similarly, the liver of the $(\mathrm{db} /+)$ fetal mouse accumulated abnormally increased amounts of glycogen, and glycogen breakdown in the placenta was delayed. An alteration in pulmonary glycogen metabolism may easily have been missed in our study because of the very short period of glycogen degradation and concomitant accelerated lung maturation in the mouse, as compared to the rat $(18,22)$. Delayed glycogen mobilization in the $(\mathrm{db} /+)$ fetal group may have been caused by alterations in the glycogenolysis or gluconeogenesis pathways, possibly due to the abnormal substrate concentrations or to hormonal changes in the mother, placenta, or fetus caused by the diabetes.

The changes observed in fetal body and organ wt and the accumulation of glycogen in placenta and liver of the $(\mathrm{db} /+)$ group may reflect alterations in organ growth and, therefore, presumably cell size and cell number. Increases in wt could be simply due to increased water content. Although we did not study wet wt/dry wt ratios, we believe our results exclude this possibility. Protein and DNA concentrations did not differ in a pattern consistent with increased tissue water. The differences in phospholipid and glycogen concentrations in lung and liver were also not compatible with increased tissue water. The differences in protein and DNA concentrations between $(\mathrm{db} /+)$ and control fetal mice varied from organ to organ. Gewolb et al. found placental hypertrophy (in spite of small fetal body wt) in fetuses of the streptozotocin rat, and interpreted changes in protein and DNA concentrations as evidence of abnormally prolonged placental growth in late gestation (23). The $(\mathrm{db} /+)$ placentas in this study showed a decreased concentration of DNA (i.e. decreased per U tissue wt) but a similar total DNA content. Therefore, they may have a similar overall number of cells that are increased in size. The increased ratio of protein to DNA in the placenta may represent a relative increase in extracellular matrix protein. The liver of the $(\mathrm{db} /+)$ fetal mouse had a decreased concentration of both DNA and protein, and an unchanged ratio of protein to DNA; PC, the predominant constitutive phospholipid of cell membranes, was markedly increased. This suggests that the $(\mathrm{db} /$ + ) fetal hepatocytes were larger, possibly to accommodate the nearly 2-fold increase in glycogen content. We found no changes in lung protein or DNA concentration, but increases in $\mathrm{PC}$ and $\mathrm{PE}$ concentrations and a decrease in PG concentration. The $(\mathrm{db} /$ + ) fetal lungs may therefore have been enlarged as a consequence of an increased number of normal-sized cells with abnormal phospholipid membranes and/or surfactant composition.

Lung maturation is altered in the fetuses of the pregnant $(\mathrm{db} /$ +) mouse, as demonstrated by increased incorporation of choline into SPC but decreased incorporation of glycerol into PG, a decreased ratio of $\mathrm{PG} / \mathrm{PI}$ synthesis, and morphologic indices of decreased airspace density and epithelial cell/total tissue ratio. The rates of synthesis of PG and PI were consistent with reciprocal changes in the lung content of $\mathrm{PG}$ and $\mathrm{PI}$. These alterations appear to represent a delay in the maturation of surfactant synthesis (25), which may occur secondary to changes in the availability of intermediary substrate (26). PG and PI synthesis, as measured by the rate of incorporation of radiolabeled precur- sors, was found by Erikkson et al. to be similarly altered in diabetic fetal lungs from rat pregnancies in which diabetes was artificially induced by streptozotocin (27).

Our observation of increased $\left[{ }^{3} \mathrm{H}\right]$ choline incorporation into SPC appears to be inconsistent with the other alterations in lung phospholipid synthesis and the morphologic appearance of delayed lung maturation in the diabetic $(\mathrm{db} /+)$ fetal lungs. Other investigators have observed a discordance among different indices used to assess lung maturation in the diabetic fetus. Sosenko et al. (28) reported no differences of SPC content in whole lung or lung lavage in fetal rabbits of alloxan-induced maternal diabetes, in whom maturation was demonstrated to be functionally delayed. Epstein et al. (29) observed an increased rate of $\left[{ }^{3} \mathrm{H}\right]$ choline incorporation into $\mathrm{PC}$ in lung slices prepared from fetuses of streptozotocin-induced diabetic rhesus monkey pregnancies, despite similar lung PC content among diabetic fetal monkeys and age-matched controls.

Increased synthesis of SPC in the fetuses of the $(\mathrm{db} /+)$ mouse could represent a specific alteration in surfactant-phospholipid production. Traditionally, SPC content or synthesis in fetal lung has been interpreted as a marker of surfactant synthesis as surfactant is relatively enriched in SPC. However, the measured synthesis of SPC in whole lung is not necessarily specific for changes in surfactant synthesis. Rieutort et al. (30), using a technique for the isolation of surfactant-rich from nonsurfactant subcellular fractions in fetal rat lungs, demonstrated that the proportion of surfactant-associated SPC to whole lung SPC ranged from a minimum of $8 \%$ to a maximum of $38 \%$ during late gestation. These observations were confirmed for fetuses of hyperinsulinemic rats (31). These authors further documented alterations in the surfactant pool of PC and SPC in diabetic or hyperinsulinemic fetuses that were not evident on analysis of total lung PC and SPC because of the relatively small contribution of surfactant to the total pool of PC and SPC. This experience suggests that caution should be used when interpreting the incorporation of a radiolabeled precursor into lung tissue PC or SPC as a measure of overall synthesis of surfactant per se, particularly as the pool sizes of various precursors inside the cells and subcellular compartments are not known and, further, as cell membranes are the major pool of both PC and SPC.

It is particularly difficult to know whether the finding of increased synthesis of PC or SPC in the fetal lung is representative of enhanced surfactant synthesis, increased turnover and remodeling attendant to processes in cellular differentiation and maturation, or merely increased demand for membrane phospholipids secondary to rapid organ growth. We believe that the increased synthesis of PC and SPC in this model reflects increased demand for phospholipids secondary to increased organ growth in the $(\mathrm{db} /+)$ group, principally because of elevated PC content, marginally increased SPC content (a 10\% increase that was significant only when considered per U lung wt), the obviously macrosomic lungs, and the knowledge that surfactant comprises a relatively small proportion of the total PC and SPC pools. We wish to emphasize, however, that this conclusion is pertinent only to the conditions of this model, and is not a criticism of the general interpretation of the experiments using PC and SPC synthesis in lung cells or slices to study surfactant synthesis. An alternative explanation might be that we have measured PC and SPC at a time when the $(\mathrm{db} /+)$ group is beginning to "catch up" in terms of the maturation of surfactant synthesis. This might appear as increased synthetic activity. The time of gestation in the fetal mouse that we studied is consistent with this hypothesis, as abundant surfactant stores normally become apparent on electron micrographs on day 18 of gestation (32). Further studies of lamellar body-specific phospholipids will be important for resolving this question.

The diabetic $(\mathrm{db} /+)$ mouse is a model of spontaneously occurring glucose intolerance in pregnancy, resulting in increased nutrient availability and utilization in the fetus and consequent macrosomia. Enhanced lung growth in the diabetic fetus coin- 
cides with altered maturation, and therefore abnormal substrate metabolism may alter the coordinated regulation of cellular growth and differentiation. As previously noted, the $(\mathrm{db} /+)$ group in these studies represents pooled fetuses with a heterogeneous genetic composition, $25 \%$ homozygous $(\mathrm{db} / \mathrm{db}), 50 \%$ heterozygous $(\mathrm{db} /+)$, and $25 \%$ normal $(+/+)$. If the inherited abnormalities of glucose metabolism in the fetus interact with maternal metabolism to cause alterations in organ growth and maturation, differences of greater magnitude may exist in isolated homozygous and heterozygous fetal mice. We have not, as yet, elucidated a method by which to identify diabetic fetuses by genetic makeup. Further studies with the $(\mathrm{db} /+)$ mouse may lead to a better understanding of the mechanisms responsible for the control of fetal development.

Acknowledgments. We thank Dr. C. Peter Fawcett for his assistance in measurements of plasma insulin levels and pancreatic insulin content.

\section{REFERENCES}

1. Robert MF, Neff RK, Hubbell JP, Taeusch HW, Avery ME 1976 Association between maternal diabetes and the respiratory distress syndrome in the newborn. N Engl J Med 29:357-360

2. Farrell PM, Engle MJ, Frantz ID, Goldman AS, Kalkhoff R, Kemnitz JW, Perelman R, Sterns JS, Susa JB 1982 Complications of pregnancy and fetal development. Diabetes 31(suppl 1):89-94

3. Coleman DL, Hummel KP 1967 Studies with the mutation, diabetes, in the mouse. Diabetologia 3:238-248

4. Chick WL, Lavine RL, Like AA 1970 Studies in the diabetic mutant mouse: V. Glucose tolerance in mice homozygous and heterozygous for the diabetes (db) gene. Diabetologia 6:257-262

5. Kaufmann RC, Amankwah KS, Dunaway G, Maroun L, Arbuthnot J, Roddick JW 1981 An animal model of gestational diabetes. Am J Obstet Gynecol 141:479-482

6. Coleman DL, Hummel KP 1974 Hyperinsulinemia in pre-weaning diabetes (db) mice. Diabetologia 10:607-610

7. Folch J, Lees M, Sloane-Stanley GH 1957 A simple method for the isolation and purification of total lipids from animal tissues. J Biol Chem 226:497509

8. Mason RJ, Nellenbogen J, Clements JA 1976 Isolation of disaturated phosphatidylcholine with osmium tetroxide. J Lipid Res 17:281-284

9. Torday JS, Carson L, Lawson EE 1979 Saturated phosphatidylcholine in amniotic fluid and prediction of the respiratory distress syndrome. $N$ Engl $J$ Med 301:1013-1018

10. Touchstone JC, Chen JC, Beaver KM 1980 Improved separation of phospholipids in thin layer chromatography. Lipids 15:61-62
11. Bartlett RG 1959 Phosphorus assay in column chromatography. J Biol Chem 234:466-471

12. Maniscalco WM, Wilson CM, Gross I, Gobran L, Rooney SA, Warshaw JB 1978 Development of glycogen and phospholipid metabolism in fetal and newborn rat lung. Biochim Biophys Acta 530:330-346

13. Herbert V, Lau KS, Gottlieb G, Bleicher SI 1965 Coated charcoal immunoassay of insulin. J Clin Endocrin Metab 25:1375-1384

14. Lowry OH, Rosebrough NJ, Farr AL, Randall RJ 1951 Protein measurement with the Folin phenol reagent. J Biol Chem 193:265-275

15. Burton K 1956 A study of the conditions and mechanisms of the diphenylamine reaction for the colorimetric determinations of deoxyribonucleic acid. Biochem J 62:315-323

16. Zar JR 1984 Biostatistical Analysis. Prentice Hall, Englewood Cliffs, NJ, pp 190-191

17. Pedersen J, Bojsen-Moller B, Poulsen H 1954 Blood sugar in newborn infants of diabetic mothers. Acta Endocrinol (Copenh) 15:33-52

18. Gewolb IH, Barrett C, Wilson C, Warshaw JB 1982 Delay in pulmonary glycogen degradation in fetuses of streptozotocin diabetic rats. Pediatr Res $16: 869-873$

19. White P 1974 Diabetes mellitus in pregnancy. Clin Perinatol 1:331-348

20. Cuezva JM, Burkett ES, Kerr DS, Rodman HM, Patel MS 1982 The newborn of diabetic rat I: hormonal and metabolic changes in the postnatal period. Pediatr Res 16:632-637

21. Bourbon JR, Pignol B, Marin L, Rieutort M, Tordet C 1985 Maturation of fetal rat lung in diabetic pregnancies of graduated severity. Diabetes 34:734743

22. Brehier A, Rooney SA 1981 Phosphatidylcholine synthesis and glycogen depletion in fetal mouse lungs: developmental changes and the effects of dexamethasone. Exp Lung Res 2:273-287

23. Gewolb IH, Barrett C, Warshaw JB 1983 Placental growth and metabolism in streptozotocin diabetic rats. Pediatr Res 17:587-591

24. Jones CT 1982 The development of the metabolism in the liver. In: Jones CT (ed) Biochemical Development of the Fetus and Neonate. Elsevier Biomedical Press, New York, pp 255-260

25. Hallman M, Kulovich M, Kirkpatrick E, Sugarman RG, Gluck L 1976 Phosphatidylinositol and phosphatidylglycerol in amniotic fluid: indices of lung maturity. Am J Obstet Gynecol 125:613-617

26. Hallman M, Epstein BL 1980 Role of myo-inositol in the synthesis of phosphatidylglycerol and phosphatidylinositol in the lung. Biochem Biophys Res Commun 92:1151-1159

27. Erikkson UJ, Tyden O, Berne C 1983 Development of phosphatidylglycerol biosynthesis in the lungs of fetuses of diabetic rats. Diabetologia 24:202-206

28. Sosenko IRS, Lawson EE, Demottaz V, Frantz ID 1980 Functional delay in lung maturation in fetuses of diabetic rabbits. J Appl Physiol 48:643-647

29. Epstein MF, Farrell PM, Chez RA 1976 Fetal lung lecithin metabolism in the glucose-intolerant rhesus monkey pregnancy. Pediatrics 47:722-728

30. Rieutort M, Farrell PM, Engle MJ, Pignol B, Bourbon JR 1986 Changes in surfactant phospholipids in fetal rat lungs from normal and diabetic pregnancies. Pediatr Res 20:650-654

31. Pignol B, Bourbon J, Ktorza A, Marin L, Rieutort M, Tordet C 1987 Lung maturation in the hyperinsulinemic rat fetus. Pediatr Res 21:436-441

32. Buckingham S, Avery ME 1962 Time of appearance of lung surfactant in the fetal mouse. Nature 193:688-689 